\title{
A STUDY OF GLINICO-PATHOLOGICAL PROFILE OF SUSPECTED AND CONFIRMED NEONATAL SEPSIS AT KATHMANDU MEDICAL COLLEGE
}

\author{
Shrestha A, Shrestha S, Basnet R
}

Department of Pediatrics, Kathmandu Medical College and Teaching Hospital, Kathmandu, Nepal

\begin{abstract}
Neonatal sepsis is a common reason for neonatal morbidity and mortality. Only clinical manifestations are inadequate to diagnose neonatal sepsis. In context of Nepal, there has been few studies correlating bacterial and clinical profile but none till now has managed to define the most adequate parameters to diagnose neonatal sepsis with certainty. Hence, this study is conducted to describe and compare clinical and laboratory characteristics of culture positive and clinically suspected sepsis (blood culture negative) and then assess whether differences exist between them. A descriptive prospective study was carried out for a period of one year starting from April 2017 to March 2018 at the NICU of Kathmandu Medical College. A total of 129 culture proven and suspected septic neonates were included. Clinical features, septic screening including blood culture, biochemical tests and radiological findings were taken into consideration. The incidence of definite neonatal sepsis was $22.4 \%$. The most common bacterial isolates were gram negative bacteria. Klebsiella spp (48\%) followed by CoNS (17\%), Acinetobacter spp (14\%), Enterobacter spp (7\%), Pseudomonas (7\%) and Staphylococcus aureus (7\%) were isolated. Different non specific clinical features like respiratory and gastro-intestinal symptoms were seen. The neonates with clinical features had positive correlation with abnormal laboratory parameters with statistically significant $p$ value, suggesting that septic neonates showed abnormal laboratory parameters. This data emphasizes the role of laboratory parameters other than blood culture for the diagnosis and empirical treatment of neonatal sepsis.
\end{abstract}

\section{KEYWORDS}

Bacterial isolates, Blood culture,

Neonatal sepsis

\section{CORRESPONDING AUTHOR}

Dr Anup Shrestha

Lecturer,

Department of Pediatrics,

Kathmandu Medical Collage and Teaching hospital.

Email: anupsrestha@gmail.com

Orcid ID: 0000-0002-1872-6497

DOI: https://doi.org/10.3126/nmcj.v22i1-2.30046 


\section{INTRODUCTION}

Neonatal mortality accounts for more than $1 / 3$ of child deaths worldwide, ${ }^{1}$ out of which, neonatal sepsis causes $1 / 4$ of total neonatal deaths. About $99 \%$ of these neonatal deaths take place in developing nations. ${ }^{2}$ Neonatal sepsis is a common reason for neonatal morbidity and mortality with an annual incidence of 2-6 per 1000 live births in the developed countries of the world ${ }^{3}$ whereas in developing countries, mortality rate due to neonatal sepsis is between 11-68/1000 live birth. ${ }^{4}$

Neonatal sepsis is defined as a clinical syndrome in an infant 28 days of life or younger, manifested by systemic signs of infection and isolation of a bacterial pathogen from the bloodstream. ${ }^{5}$ Group B Streptococcus (GBS), a gram positive organism, is the most common organism of neonatal sepsis in Europe and North America. But there is dominance of gram negative organism in developing countries. ${ }^{6}$

Only clinical manifestations are inadequate to diagnose neonatal sepsis. Alertness to these manifestations can be very important though, which can often represent early signs of sepsis. Staffs involved in Neonatal intensive care unit (NICU) need to identify these suspicious signs, besides other factors, supporting a prompt diagnosis. $^{7}$

Early recognition and diagnosis of neonatal septicemia is difficult because of nonspecific clinical presentation as well as equivocal laboratory findings. Blood culture is considered gold standard for the diagnosis, but is time consuming. ${ }^{8,9}$ Nevertheless, even blood cultures are not free from error as it can be falsely sterile because of low yield caused by intermittent or low-density bacteremia, inadequate sample volume or suppression of bacterial growth by earlier maternal intra-partum antibiotic administration. ${ }^{10}$

The diagnosis is hampered by unclear and nonspecific manifestation. However, it is crucial that treatment is initiated early in these cases because of the high mortality associated with neonatal septicemia. In context of our country there has been few studies correlating bacterial and clinical profile but no study till now has managed to define the most adequate parameters to diagnose neonatal sepsis with certainty.

This study was conducted to describe and compare the clinical and laboratory characteristics of culture positive (proven sepsis) and clinically suspected neonatal sepsis (blood culture negative), and then assess whether differences exist between them. Also, this study aimed to correlate between clinical features of neonatal sepsis and laboratory parameters. This study tried to establish relationship between the specific clinical features demonstrated by certain bacteria isolated from blood culture so as to start the specific treatment before the time consuming reports of blood culture. Likewise, role of other laboratory parameters like leukocytosis/ leucopenia, raised C-reactive protein and chest $\mathrm{X}$-ray is also established.

\section{MATERIALS AND METHODS}

A descriptive study was carried out from April 2017 to March 2018 based on prospective data collected in neonatal intensive care unit (NICU) of Kathmandu Medical College Teaching Hospital (KMCTH). Approval for this research was obtained from the ethical committee of KMCTH.

Newborns of gestational age $>28$ weeks and irrespective of birth weight, diagnosed as culture proven or suspected sepsis hospitalized in NICU and special care baby unit (SCBU) were included in this study.

The diagnosis of suspected sepsis was based on any of two following clinical features: increased work of breathing, hypothermia, hyperthermia, poor feeding, seizure, lethargy, apnea, bleeding, cyanosis, jaundice, diarrhea, vomiting and abdominal distension and any of two following laboratory criteria (white blood cell count $<7500$ or $>25,000 / \mathrm{mm}^{3}$; immature/ total neutrophil (I/T) ratio $>0.2$; platelet count $<100,000 \times 10^{9} / 1$; raised C-reactive protein (CRP). ${ }^{17}$

After recruitment, $1.5-2 \mathrm{ml}$ peripheral blood sample was collected after six hours of birth using aseptic technique, $0.5-1 \mathrm{ml}$ of which was inoculated into the Brain Heart Infusion broth. The remaining portion was used for estimation of CRP and total leukocyte count, platelet count, PBS, micro ESR and I/T ratio. All the samples were transported at room temperature as soon as possible. Repeat samples were sent after 72 hours, if the child was not improving despite using empirical antibiotics. When blood cultures were positive, antibiotics were changed according to sensitivity pattern. In case of a negative blood culture, when the child was still symptomatic then the empirical antibiotics were upgraded according to the NICU protocol.

Whenever a true pathogen was isolated from a normally sterile body fluid along with laboratory findings and clinical signs of neonatal sepsis, it was termed as confirmed neonatal sepsis. Every other case was labeled as suspected sepsis. The clinical signs and symptoms were analyzed by pediatrician using all the standard clinical protocol. The total leucocyte count was done by 
automated coulter analyzer LH 500; Peripheral blood was stained with giemsa stain and band cells and toxic granules were noted. CRP latex slide method (agglutination method) was used for CRP. Cerebro-spinal fluid analysis was done in all cases of positive blood culture and clinical features compatible with meningitis. Urine culture was done only in cases with congenital hydronephrosis, admission after 3 days of life and prolonged jaundice. All the data were tabulated in the Microsoft Excel and further statistical analysis was done using SPSS software version 17.

\section{RESULTS}

The total number of cases enrolled in the present study was 129 . There was male predominance among the neonates with male: female ratio of $1.2: 1$. This study showed that majority of newborns were delivered at term via cesarean section, out of which $34 \%$ were low birth weight. The term to preterm ratio was 3:1. The demographics are tabulated in Table 1.

\begin{tabular}{|c|c|c|c|}
\hline Sex & Male: Female & 72: 57 & 1.2: 1 \\
\hline Gestation & Term: Preterm & 97: 32 & $3: 1$ \\
\hline $\begin{array}{l}\text { Type of } \\
\text { delivery }\end{array}$ & $\begin{array}{l}\text { Normal } \\
\text { vaginal } \\
\text { delivery: } \\
\text { Cesarean } \\
\text { section }\end{array}$ & 60: 69 & $0.8: 1$ \\
\hline Birth weight & $\begin{array}{l}\text { Low weight: } \\
\text { Normal } \\
\text { weight }\end{array}$ & $44: 85$ & $0.5: 1$ \\
\hline
\end{tabular}

\section{Distribution of risk factors:}

Total of 129 cases were studied for maternal risk factors out of which, 68 cases (53\%) had maternal risk factors. The risk factors were premature rupture of membrane, failed induction, preterm labor, meconium stained liquor, fetal distress,

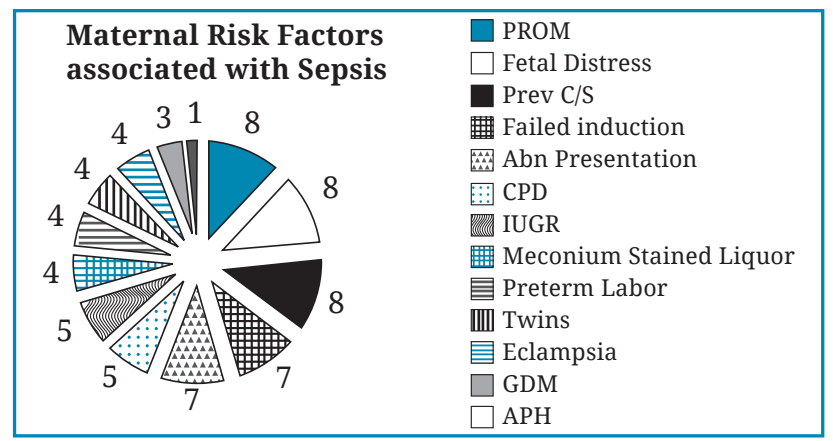

Fig. 1: Chart illustrating association of maternal risk factors with neonatal sepsis abnormal presentation, previous cesarean section, multiple pregnancy, eclampsia, IUGR and gestational diabetes. Among these factors, fetal distress, premature rupture of membrane and previous cesarean sections were the most common (Fig. 1).

Table 2: Septic Screening in Septic Neonates

\begin{tabular}{lcc|} 
Investigation & Number of cases & $\%$ \\
TLC (leucocytosis: & 20 & 70 \\
$>25000)$ & 10 & 34 \\
ANC (<5000) & 21 & 72 \\
CRP (Positive) & 02 & 7 \\
$\begin{array}{l}\text { Platelets <1,00,000 / } \\
\text { cmm }^{3}\end{array}$ & & \\
\hline
\end{tabular}

Table 3: The following table depicts all the clinical features present in the septic neonates in relation to specific bacterial isolates.

Microorganism
isolated

\section{Specific clinical features}

\begin{tabular}{|c|c|}
\hline Klebsiella spp & $\begin{array}{lr}\text { Fever, seizure, } & \text { irritability, } \\
\text { lethargy, } & \text { feeding } \\
\text { intolerance, } & \text { abdominal } \\
\text { distension, } & \text { jaundice, } \\
\text { vomiting, } & \text { cyanosis, } \\
\text { increased work of breathing, } & \end{array}$ \\
\hline $\begin{array}{l}\text { Staphylococcus } \\
\text { aureus }\end{array}$ & $\begin{array}{l}\text { Increased work of breathin } \\
\text { abdominal distensio } \\
\text { apnea, fever. }\end{array}$ \\
\hline $\begin{array}{l}\text { Pseudomonas } \\
\text { spp }\end{array}$ & $\begin{array}{l}\text { Increased work of breathir } \\
\text { poor perfusion, abdomir } \\
\text { distension, lethargy, po } \\
\text { sucking/feeding intoleran }\end{array}$ \\
\hline
\end{tabular}

Acinetobacter Apnea, bradycardia, poor spp perfusion.

Enterobacter

Poor perfusion, feeding spp

CoNS intolerance, increased work of breathing.

Poor perfusion, feeding intolerance, apnea, fever, increased work of breathing

\section{Incidence of neonatal sepsis}

Twenty nine (22.4\%) cases out of total 129 suspected cases showed positive blood culture. The incidence of definite sepsis was $22.4 \%$ and the incidence of definite sepsis in preterm was $63 \%$.

\section{Septic screening in septic neonates (Table 2)}

Of the confirmed septic neonates, $70 \%$ showed leucocytosis whereas absolute neutrophil count 
was reduced only in $34 \%$. CRP was positive in $72 \%$ and thrombocytopenia was seen in only $7 \%$ which correlated well with clinical diagnosis and clinical features in the neonates.

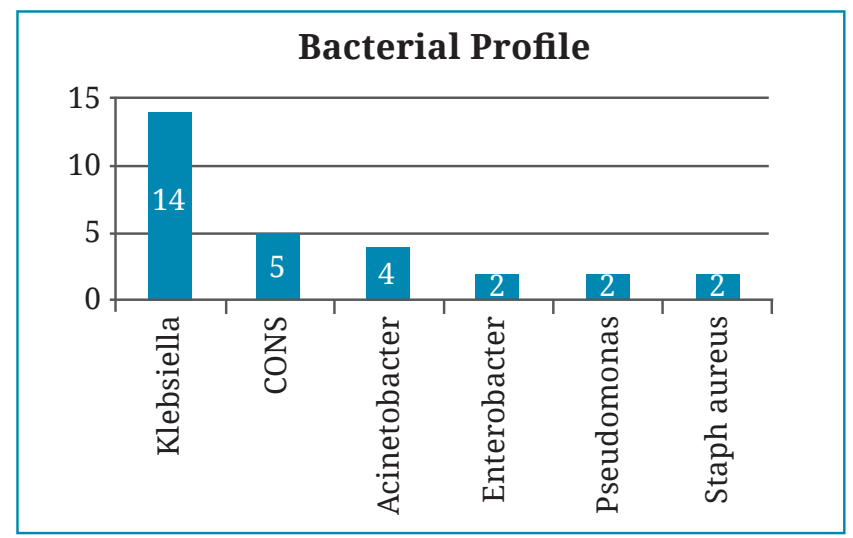

Fig. 2: Bacterial Profile in Neonatal Sepsis.

\section{Profile of bacterial isolates from blood culture (Fig 2)}

Gram negative organisms were more prevalent isolates in blood culture. Majority of the organism were gram negative which included Klebsiella spp, Pseudomonas spp, Acinetobacter spp, and Enterobacter spp. Klebsiella pneumoniae was the most common isolate accounting for 14 cases (48\%). Rest were CoNS ( $\mathrm{n}=5 ; 17 \%)$, Acinetobacter $\operatorname{spp}(\mathrm{n}=4 ; 14 \%)$, Enterobacter $\operatorname{spp}(\mathrm{n}=2 ; 7 \%)$,
Pseudomonas spp $(\mathrm{n}=2 ; 7 \%)$ and $S$. aureus $(\mathrm{n}=2$; $7 \%)$. The varied clinical features shown by different bacterial isolates are shown in Table 4

\section{Correlation between clinical features and laboratory parameters}

The presence or absence of clinical features was correlated with laboratory parameters which included hematological, biochemical and radiological parameters. The hematological variables included were total leucocyte count, platelet count, band cell and toxic granules and raised CRP. Biochemical variables were glucose level, total and direct bilirubin level. Radiological variables included chest X-ray including abdominal X-ray findings.

The following table shows correlation between clinical features and laboratory parameters. There was statistically significant correlation between presence of clinical features and laboratory parameters.

\section{DISCUSSION}

Septicemia in neonates refers to generalized bacterial infection documented by a positive blood culture in the first 4 weeks of life. ${ }^{11}$

Total of 129 cases of suspected neonatal sepsis were enrolled in this study. Among the suspected

\section{Table 4: Cinical features shown by different bacterial isolates.}

\begin{tabular}{|c|c|c|c|c|c|c|c|c|c|}
\hline Organism & $\begin{array}{l}\text { Poor } \\
\text { Perfu- } \\
\text { sion }\end{array}$ & Apnea & Fever & Seizure & Cyanosis & $\begin{array}{l}\text { Abdominal } \\
\text { Distension }\end{array}$ & $\begin{array}{c}\text { Feeding } \\
\text { intoler- } \\
\text { ance }\end{array}$ & $\begin{array}{l}\text { Increased } \\
\text { work of } \\
\text { breathing }\end{array}$ & Jaundice \\
\hline Klebsiella spp & 6 & 8 & 8 & 2 & 2 & 7 & 7 & 8 & 10 \\
\hline CONS & 1 & 3 & 3 & & & & 1 & 10 & \\
\hline $\begin{array}{l}\text { Enterobacter } \\
\text { spp }\end{array}$ & 2 & & & & & & 2 & 2 & \\
\hline $\begin{array}{l}\text { Pseudomonas } \\
\text { spp }\end{array}$ & 1 & & & & & 1 & 2 & 3 & \\
\hline $\begin{array}{l}\text { Acinetobacter } \\
\text { spp }\end{array}$ & 1 & 1 & & & & & & & \\
\hline S. aureus & & 1 & 1 & & & 2 & & 4 & \\
\hline
\end{tabular}

Table 5: Correlation between clinical features and laboratory parameters

\begin{tabular}{|lllll|} 
& & $\begin{array}{l}\text { Laboratory parameters (Hematological, } \\
\text { Biochemical and Radiological features }\end{array}$ & $\begin{array}{l}\text { P value } \\
(<0.05)\end{array}$ \\
\hline \multirow{4}{*}{ Clinical features } & Positive & Negative & \\
& Present & 20 & 4 & $\mathbf{0 . 0 1}$ \\
& Absent & 1 & 4 & \\
\hline
\end{tabular}


septic neonates, 1.2:1 male predominance was noted. This finding is similar to study done by Ansari et $a l^{12}$ from Nepal, Karambin and Zarkesh from Iran ${ }^{13}$ and Al-Shamahy et $a l^{14}$ from Yemen. Most of the neonates had term delivery with term to pre-term ratio of 3:1. Mode of delivery was cesarean section (53\%) and vaginal delivery (47\%). Normal birth weight to low birth weight was $2: 1$. The incidence of neonatal sepsis found in this study was $22.4 \%$, which is similar to incidence reported by Shin et al. ${ }^{15}$

The most important risk factors for neonatal sepsis were prematurity and low birth weight as stated by Jain et $a l^{16}$ in a study done in Western Nepal. Whereas, this study showed that the commonest risk factors were premature rupture of membrane, previous cesarean section and fetal distress.

The most common organisms responsible for neonatal sepsis were gram negative organisms and the most common isolate was Klebsiella spp accounting for $14(48 \%)$ out of 29 cases. This finding is also similar to other studies. A study done at Dhulikhel hospital showed that Gram negative organisms were $60.64 \%$ amongst them, Klebsiella spp was the most often encountered followed by Pseudomonas spp. ${ }^{17}$ Naderi-Nasab et $a l^{18}$ stated that gram positive organisms were more frequent than gram negative organisms in nosocomial and acquired infections in NICUs of Mashhad, Iran. Also, in a study on the Pakistani population done by Aftab et al, ${ }^{19}$ Escherichia coli was the most common organism followed by Klebsiella spp, and among the gram positive organisms, S. aureus was most frequent.

Most of the previous reports have emphasized on the pivotal role of gram-negative organisms such as E. coli, Klebsiella spp and S. aureus as main pathogens causing neonatal sepsis. ${ }^{20}$ Most of the studies have found a preponderance of gram negative organisms like Klebsiella spp, Pseudomonas spp, and Enterobacter species. ${ }^{21}$ Hence, this study correlated well with other studies in term of bacterial isolates in neonatal sepsis.

Increased work of breathing was found to be the most common clinical presentation in this study which is similar to other studies done by Jain et al. ${ }^{16}$ This study showed that Klebsiella spp presented mostly with respiratory symptoms but respiratory symptoms were seen in other isolates as well. Besides respiratory symptoms, there were other symptoms as well like jaundice, fever, poor feeding seizure etc. CoNS infection had respiratory, gastro-intestinal symptoms as well as fever and poor perfusion. S. aureus infection showed respiratory symptoms along with fever and gastro-intestinal symptoms as well. Pseudomonas infection had respiratory as well as gastro-intestinal symptoms. Hence, specific clinical feature was not seen in specific bacterial infection. Thus, specific clinical features cannot be specified to any isolates. Hence, this study concludes that the clinical features can be varied in cases of neonatal sepsis and any specific clinical feature cannot be coined to any specific organism in septic neonate.

Among the septic screening, leucocytosis and raised C-reactive protein correlated very well with the diagnosis and clinical features whereas some cases (34\%) had neutropenia. Thrombocytopenia correlated least among them. However, most of other studies showed that CRP was the most potent biomarker as suggested by Jain et $a l^{16}$ and Hedegaard et al. ${ }^{22}$

The correlation between clinical features was compared with positive findings in laboratory parameters. The clinical features were divided into respiratory, gastro-intestinal and neurological symptoms and others (hematological) features. Laboratory parameters included hematological features like leucocytosis or leucopenia, thrombocytopenia, raised ESR or positive CRP, presence of band cells or toxic granules in peripheral smear. Radiological features included chest infiltrates and in abdominal X- ray showing features of necrotising enterocolitis like dilated bowel loops, pneumatosis intestinalis, pneumoperitoneum etc. Biochemical parameter included presence of hyperbilirubinemia or hypoglycemia. The correlation was statistically significant with $\mathrm{p}$ value of 0.01 suggesting that septic neonates showed abnormal laboratory parameters, hence there is important role of laboratory parameters in septic neonates. This data emphasizes the role of laboratory parameters other than blood culture. Hence, empirical treatment can be started before the blood culture report is obtained which is time consuming. The antibiotic sensitivity pattern of these bacterial isolates was not regarded in this study.

To summarize, the incidence of definite neonatal sepsis was $22.4 \%$ and the incidence of sepsis in preterm was $63 \%$. The most common bacterial isolates were gram negative bacteria. Klebsiella spp accounted for $48 \%$ (14 cases) followed by CoNS (17\%), Acinetobacter spp (14\%), Enterobacter spp (7\%), Pseudomonas spp (7\%) and S. aureus (7\%). There were varied non specific clinical features. Respiratory features were the commonest clinical feature followed by gastro-intestinal symptoms. The neonates with clinical features had positive correlation with abnormal laboratory parameters with $\mathrm{p}$ value of less than 0.05 . 


\section{ACKNOWLEDGEMENTS}

I would like express my sincere gratitude to my colleagues (Dr. Sabina Shrestha and Dr. Rydam Basnet for helping in the data collection and analysis) as well as all the staffs (nurses, residents and interns of Department of Pediatrics). I would also like to thank Head of Department Sir Prof. Dr. Pushpa Raj Sharma (for the guidance and supervision) and the entire laboratory and radiology technician for helping me out during the study period.

\section{REFERENCES}

1. Rajaratnam JK, Marcus JR, Flaxman AD, Wang $\mathrm{H}$, Levin-Rector A, Dwyer L. Neonatal, post neonatal, childhood, and under-5 mortality for 187 countries, 1970-2010: a systematic analysis of progress towards Millennium Development Goal 4. Lancet 2010; 375: 1988-2008.

2. Lawn JE, Cousens S, Zupan S. 4 million neonatal deaths: when? where? why? Lancet 2005; 365: 891900.

3. Jana AK, Sridhar S. Clinical diagnosis of sepsis. J Neonatol 2009; 23: 44-7.

4. Rasul CH, Hassan MA, Habibullah M. Neonatal sepsis and use of antibiotic in a tertiary care hospital. PakJ Med Sci 2007; 23: 78-81.

5. Edwards MS, Baker CJ. Sepsis in the newborn. In: Gershon AA, Hotez PJ, Katz SL (eds). Krugman's Infectious Diseases of Children. 11th ed. Philadelphia, PA: Mosby; 2004: 545.

6. Dawodu A, al Urman K, Twum-Danso K. A case control study of neonatal sepsis: experience from Saudi Arabia. J Trop Pediatr 1997; 43: 84-8.

7. Meireles LA, Vieira AA, Costa CR. Evaluation of the neonatal sepsis diagnosis: use of clinical and laboratory parameters as diagnosis factors. Rev Esc Enferm USP 2011; 45: 32-8.

8. Seema, Kumar R, Mandal RN et al. Serum TNF alpha and free radical scavengers in neonatal septicemia. Indian J Pediatr 1999; 66: 511-16.

9. Buch AC, Srivastava V, Kumar H, Jadhav PS. Evaluation of hematological profile in early diagnosis of clinically suspected cases of clinically cases of neonatal sepsis. Int'l J Basic Appl Med Sci 2011; 1: 1-6.

10. Bhutta ZA, Yusuf K. Early-onset neonatal sepsis in Pakistan: a case control study of risk factors in a birth cohort. Am J Perinatol 1997; 14: 577-81.

11. Singh M, Deorari AK, Khajuria RC, Paul VK. Perinatal \& neonatal mortality in a hospital. Indian J Med Res 1991; 94: 1-5.

12. Ansari S, Nepal HP, Gautam R, Shrestha S, Neopane P, Chapagain ML. Neonatal septicemia in Nepal:
Early-onset versus late-onset. Int'l J Pediatr 2015; 379806: 6 .

13. Karambin MM, Zarkesh M. Enterobacter, the most common pathogen of neonatal septicemia in Rasht, Iran. Iran J Pediatr 2011; 21: 83-7.

14. Al-Shamahy HA, Sabrah AA, Al-Robasi AB, Naser SM. Types of bacteria associated with neonatal sepsis in Al-Thawra University Hospital, Sana'a, Yemen, and their antimicrobial profile. Univ Med J 2012; 12: 48-54.

15. Shin YJ, Ki M, Foxman B. Epidemiology of neonatal sepsis in South Korea. Pediatr Int'l 2009; 51: 225-32.

16. Jain NK, Jain VM, Maheshwari S. Clinical Profile of Neonatal Sepsis. Kathmandu Univ Med J 2003; l: 117-20.

17. Shrestha S, Shrestha NC, Dongol Singh S et al. Bacterial isolates and its antibiotic susceptibility pattern in NICU. Kathmandu Univ Med J 2013; 11: 66-70.

18. Naderi-Nasab M, Farhat A, Tajzadeh P, Sourosh S, Amiri M. Study of the bacterial agents in nosocomial and acquired infections based on the blood culture in neonatal intensive care unit of a hospital, north east of Iran. Saudi Med J 2007; 28: 723-6.

19. Aftab R, Iqbal I. Bacteriological agents of neonatal sepsis in NICU at Nishtar Hospital Multan. J Coll Physicians Surg Pak 2006; 16: 216-9.

20. Afsharpaiman S, Torkaman M, Saburi A, Faarzaampur A, Amirsalari S, Kavehmanesh Z. Trends in incidence of neonatal sepsis and antibiotic susceptibility of causative agents in two neonatal intensive care units in Tehran, IR Iran. $J$ Clin Neonatol 2012; 1: 124-30.

21. Shaw CK, Shaw P, Thapalial A. Neonatal sepsis bacterial isolates and antibiotic susceptibility patterns at a NICU in a tertiary care hospital in western Nepal: A retrospective analysis. Kathmandu Univ Med J 2007; 5: 153-60.

22. Hedegaard SS, Wisborg K, Hvas AM. Diagnostic utility of biomarkers for neonatal sepsis--a systematic review. Infect Dis (Lond) 2015; 47: 11724. 